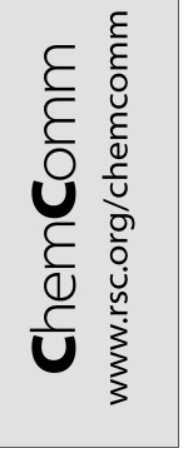

\title{
Microwave single walled carbon nanotubes purification
}

\author{
M. T. Martínez, ${ }^{* a}$ M. A. Callejas, ${ }^{a}$ A. M. Benito, ${ }^{a}$ W. K. Maser, ${ }^{a}$ M. Cochet, $^{a}$ J. M. Andrés, ${ }^{a}{ }^{J}$. \\ Schreiber, $^{b}$ O. Chauvet ${ }^{b}$ and J. L. G. Fierro ${ }^{c}$ \\ a Instituto de Carboquímica (CSIC), C/Miguel Luesma Castán, 4, 50015 Zaragoza, Spain. \\ E-mail:mtmartinez@carbon.icb.csic.es \\ ${ }^{b}$ Institut des Matériaux Jean Rouxel, LPC, 2 rue de la Houssinière, F-44322 Nantes Cedex 3, France \\ c Instituto de Catálisis y Petroleoquímica (CSIC), Cantoblanco, 28048 Madrid, Spain
}

Received (in Cambridge, UK) 13th February 2002, Accepted 21st March 2002

First published as an Advance Article on the web 8th April 2002

A new single walled carbon nanotubes (SWCNTs) purification procedure has been developed; it consists in a combination of air treatment and acid microwave digestion leading to a high purity SWCNTs material; the procedure reaches high metal removal percentages and the operation time is drastically reduced compared to conventional acid reflux treatments.

The production of SWCNTs in macroscopic amounts ${ }^{1-3}$ has led to a significant amount of research on the physical and chemical properties of this unique material. Their potential uses range from components in integrated circuits, logic gates, flat panel displays to nanoscale motors. ${ }^{4-6}$ Nevertheless, challenges remain in the control of their fabrication and purification before carbon nanotubes can be used for technological applications. Most of SWCNTs purification methods 7 involve oxidation using mineral acids and/or gas phase oxidation to remove catalytic metal particles and amorphous carbon. So far, these processes are not very efficient especially concerning the removal of impurities and require long treatment times.

In this work, a new method to purify SWCNTs is described. The method takes advantage of the ability of microwaves to homogeneously heat a solution while stirring at molecular dipole level. The disruption and recomposition of the dipoles at high frequency considerably improves the diffusion rates and the transport properties. ${ }^{8}$ This leads to high percentages of metal removal and drastically reduced operation times compared to the conventional acid reflux methods.

SWCNTs were produced by the arc-discharge method using $\mathrm{Ni} / \mathrm{Y}$ (4/1 atomic ratio) in the graphite precursor. ${ }^{1}$ The as-grown soot sample was subjected to acid treatments in a high performance microwave digestion unit (mls $1200 \mathrm{mega}) .3 \mathrm{M}$ $\mathrm{HNO}_{3}$ and $\mathrm{HCl}(37 \mathrm{wt} \%$ ) acid solutions at different conditions of time and temperature were used. The resulting suspensions were centrifuged ( $10000 \mathrm{rpm}$ for $4 \mathrm{~h}$ ) and the supernatant acids were decanted off. The sediments were re-suspended in deionized water, three times centrifuged and decanted and finally vacuum filtered on $3 \mu \mathrm{m}$ pore polycarbonate filter membrane.

In order to remove the amorphous carbon after the microwave treatment, the samples were oxidised at $300{ }^{\circ} \mathrm{C}$ for 90 minutes and finally annealed for $10 \mathrm{~h}$ at $950{ }^{\circ} \mathrm{C}$ in a stream of argon. The purified samples were characterised by inductive coupled plasma spectroscopy (ICPS), X-ray photoelectron spectroscopy (XPS), Raman spectroscopy, scanning electron microscopy (SEM) and transmission electron microscopy (TEM).

The Ni and Y content of the raw material as well as the samples treated under different conditions in the microwave

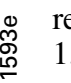
reactor were determined by ICPS and are indicated in Table

It can be seen that $\mathrm{HNO}_{3}$ treatments result in higher removal of $\mathrm{Ni}$ and $\mathrm{Y}$ than $\mathrm{HCl}$ treatments. A temperature increase improved the nickel removal for both the $\mathrm{HNO}_{3}$ and the $\mathrm{HCl}$ treatments, being considerably higher for $\mathrm{HNO}_{3}$

For $\mathrm{HNO}_{3}$ treatments at $100{ }^{\circ} \mathrm{C}$, reaction times longer than 2 $\mathrm{h}$ led to higher metal concentration in the resultant material. The
Table 1 Microwave treatments carried out on as grown SWCNTs and corresponding metal contents

\begin{tabular}{|c|c|c|}
\hline Acid/temperature/time & $\mathrm{Ni}(\mathrm{wt} \%)$ & $\mathrm{Y}(\mathrm{wt} \%)$ \\
\hline Raw material & 17.5 & 2.6 \\
\hline $3 \mathrm{M} \mathrm{HNO}_{3} / 100{ }^{\circ} \mathrm{C} / 1 \mathrm{~h}$ & 6.3 & 0.8 \\
\hline $3 \mathrm{M} \mathrm{HNO}_{3} / 100{ }^{\circ} \mathrm{C} / 2 \mathrm{~h}$ & 3.4 & 0.7 \\
\hline $3 \mathrm{M} \mathrm{HNO}_{3} / 100{ }^{\circ} \mathrm{C} / 3 \mathrm{~h}$ & 8.0 & 1.7 \\
\hline $3 \mathrm{M} \mathrm{HNO}_{3} / 200^{\circ} \mathrm{C} / 1 \mathrm{~h}$ & 3.1 & 0.7 \\
\hline $3 \mathrm{M} \mathrm{HNO}_{3} / 200^{\circ} \mathrm{C} / 2 \mathrm{~h}$ & 3.0 & 1.1 \\
\hline $37 \mathrm{wt} \% \mathrm{HCl} / 100^{\circ} \mathrm{C} / 1 \mathrm{~h}$ & 14.2 & 2.0 \\
\hline $37 \mathrm{wt} \% \mathrm{HCl} / 200^{\circ} \mathrm{C} / 1 \mathrm{~h}$ & 12.6 & 1.9 \\
\hline $37 \mathrm{wt} \% \mathrm{HCl} / 200^{\circ} \mathrm{C} / 2 \mathrm{~h}$ & 11.9 & 2.2 \\
\hline
\end{tabular}

highest metal removal was reached with a $3 \mathrm{M} \mathrm{HNO}_{3}$ solution at $200{ }^{\circ} \mathrm{C}$ for $1 \mathrm{~h}$. By increasing the digestion time from 1 to 2 $\mathrm{h}$ no further removal was achieved at this temperature. This indicates that there is a small amount of metals associated to the SWCNTs material difficult to remove as has also been reported by Dujardin et al. ${ }^{9}$

To investigate the nature of the metals easily removed and those remaining in the sample after the purification process, the raw and acid treated samples were analysed by XPS. Ni $2 p$ and Y 3d core-level spectra of the raw sample were recorded and are shown in Fig. 1. The most intense peak of nickel, the Ni $2 p_{3 / 2}$, presents two components, one at $854 \mathrm{eV}(77 \%)$ and another one less intense at $856.5 \mathrm{eV}(23 \%)$. The first component is located $1.8 \mathrm{eV}$ above the position of metallic nickel. Such a large shift can not be attributed to size effects but rather to the formation of a nickel compound and could correspond to a nickel carbide layer formed at the surface of the metallic nickel particle. The second component is characteristic of $\mathrm{Ni}^{2+}$ ions in an oxygen environment ${ }^{10}$ and could be due to a very thin layer of nickel oxide since no satellite line is detected. The Y $3 \mathrm{~d}$ core-level spectrum displays the characteristic $\mathrm{Y} 3 \mathrm{~d}_{5 / 2} / \mathrm{Y} 3 \mathrm{~d}_{3 / 2}$ doublet with the former peak at $156.8 \mathrm{eV}$ (Fig. 1). The binding energy (BE) of the $\mathrm{Y} 3 \mathrm{~d}_{5 / 2}$ component is located a little above the usual position of the $\mathrm{Y}_{2} \mathrm{O}_{3}(156.4 \mathrm{eV})$, which obviously corresponds to $\mathrm{Y}^{3+}$ in an environment of oxygen atoms. These results point out that the metal nanoparticles are superficially oxidised or/and are surrounded by a a few layers of metal carbides since no
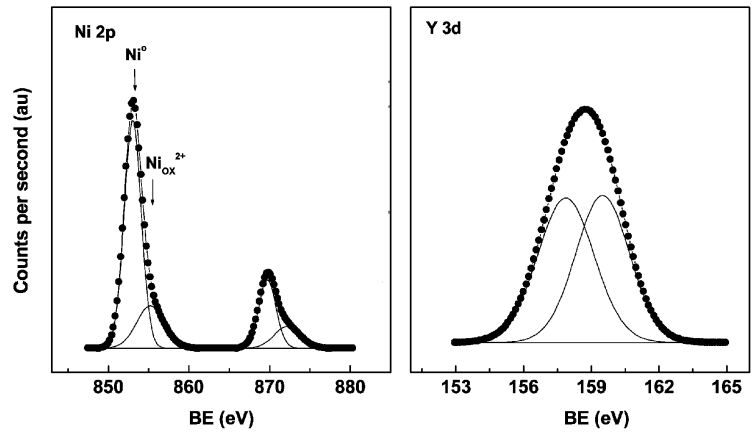

Fig. $1 \mathrm{Ni} 2 \mathrm{p}$ and Y $3 \mathrm{~d}$ XPS spectra of the as grown SWCNTs. 
binding energies corresponding to metallic states are determined by XPS.

In contrast to the ICPS data, the XPS analysis on the treated samples did not show any signal corresponding to $\mathrm{Ni}$ and $\mathrm{Y}$.

This shows that the Ni and Y content, as determined by ICPS, was in the form of nanoparticles covered by carbon layers which prevent their detection by a surface sensitive technique such as XPS. This suggests that this carbonaceous material covering the metal nanoparticles hinders their removal by the acid treatments.

Going one step further, the acid treated sample was sputtered with $\mathrm{Ar}^{+}$ions at $2 \mathrm{keV}$ for $5 \mathrm{~min}$ to pull up the carbon layers covering the metallic nanoparticles. After this treatment, the XPS technique detected the presence of $\mathrm{Ni}$ with the same $\mathrm{BE}$ as the raw sample; the $\mathrm{Ni} 2 \mathrm{p}_{3 / 2}$ peak showed two components at $854 \mathrm{eV}(69 \%)$ and $856.5 \mathrm{eV}(31 \%)$ and $\mathrm{Y}$ in trace amounts. This indicates that the remaining metal nanoparticules not removed by the acid treatment were in the same oxidation state as those removed in the purification step clearly pointing out that the carbonaceous material covering the metal particles prevents their elimination.

To make the metal nanoparticles more accesible to the acid treatment, the raw samples were oxidised in air at $350{ }^{\circ} \mathrm{C}$ before the microwave treatments. In Table 2 , the metallic contents of the air pre-treated and subsequently microwave treated samples are shown.

Table 2 Microwave treatments carried out on air oxidised SWCNTs

\begin{tabular}{lll}
\hline Oxidation/acid/temperature/time & $\mathrm{Ni}(\mathrm{wt} \%)$ & $\mathrm{Y}(\mathrm{wt} \%)$ \\
\hline $350{ }^{\circ} \mathrm{C}, 10 \mathrm{~min} / 37 \mathrm{wt} \% \mathrm{HCl} / 100{ }^{\circ} \mathrm{C} / 1 \mathrm{~h}$ & 6.1 & 1.2 \\
$350^{\circ} \mathrm{C}, 10 \mathrm{~min} / 3 \mathrm{M} \mathrm{HNO} / 100^{\circ} \mathrm{C} / 1 \mathrm{~h}$ & 3.7 & 0.6 \\
$350^{\circ} \mathrm{C}, 1 \mathrm{~h} / 3 \mathrm{M} \mathrm{HO} \mathrm{HN}_{3} / 100^{\circ} \mathrm{C} / 1 \mathrm{~h}$ & 1.7 & 0.4 \\
$350^{\circ} \mathrm{C}, 1 \mathrm{~h} / 3 \mathrm{M} \mathrm{HNO} / 200{ }^{\circ} \mathrm{C} / 1 \mathrm{~h}$ & 2.4 & 1.2 \\
\hline
\end{tabular}

The best results were obtained after air treatment for $1 \mathrm{~h}$ at $350{ }^{\circ} \mathrm{C}$ and $3 \mathrm{M} \mathrm{HNO}_{3}$ at $100{ }^{\circ} \mathrm{C}$ for $1 \mathrm{~h}$. It can be seen that by increasing the temperature to $200^{\circ} \mathrm{C}$ the amount of metal after the microwave treatment is higher than after the treatment at $100{ }^{\circ} \mathrm{C}$. This is due to a higher destruction of carbonaceous material under more severe conditions as can be deduced from the lower yields of material recovered, $56 \mathrm{wt} \%$ at $100{ }^{\circ} \mathrm{C}$ and 39 wt $\%$ at $200{ }^{\circ} \mathrm{C}$.

As general result, the combined treatment enhances the metal removal considerably. Nevertheless, some metal nanoparticules remain, probably those covered by defect-free graphitic material not oxidised during the thermal pre-treatment.

The yields of the remaining material after each purification step were: $55 \mathrm{wt} \%$ for the pre-oxidation treatment, $56 \mathrm{wt} \%$ for the microwaves acid digestion, $34 \mathrm{wt} \%$ for the post-oxidation step and $85 \mathrm{wt} \%$ for the annealing.

The evolution of the carbonaceous material with the purification process was followed by Raman spectroscopy. The Raman spectra (excitation line $514 \mathrm{~nm}$ ) in Fig. 2, show in all cases the radial breathing modes (RBM) in a range of frequencies from 140 to $210 \mathrm{~cm}^{-1}$ characteristic of the SWNTs as well as the splitted tangential modes at $1500-1600 \mathrm{~cm}^{-1}$ indicating the presence of SWCNTs in all samples. After the microwave acid treatment, an increase of the D band around $1350 \mathrm{~cm}^{-1}$ can be seen indicating the presence of amorphous carbon probably formed due to the partial destruction of the SWNTs. However, subsequent thermal treatments result in a decrease of the $\mathrm{D}$ band pointing out the removal and reorganisation of amorphous carbon with the oxidation steps.

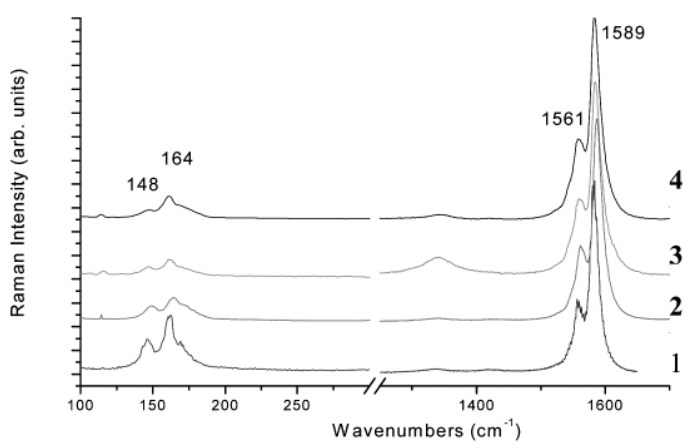

Fig. 2 Raman spectra at $514 \mathrm{~nm}$ of the raw SWCNT sample (1), the preoxidised sample (2), the microwave treated sample (3), and the postoxidised sample (4)
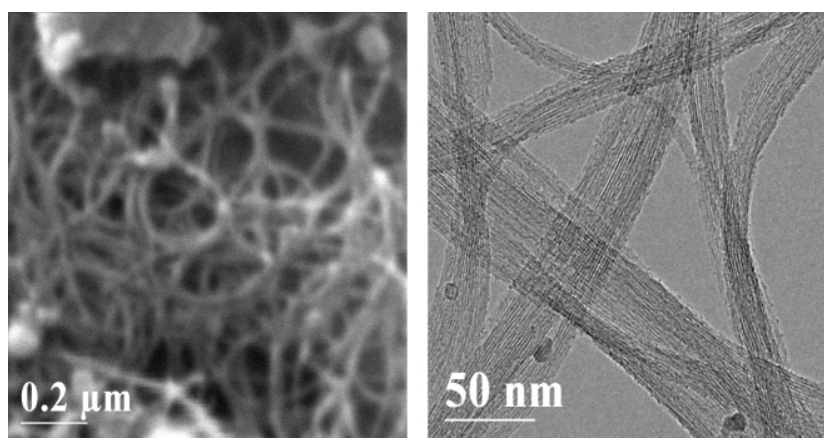

Fig. 3 SEM and TEM images of the purified SWNT material.

After the final annealing step, a high purity SWCNT material has been obtained as can be seen by SEM and TEM (Fig. 3).

Summarising, we have developed an efficient purification procedure that drastically reduces the treatment time to $1 \mathrm{~h}$ compared to conventional acid reflux times of $45 \mathrm{~h}$ and this process results in high purity SWNT material.

This work was supported by the EC RTN contract NANOCOMP (HPRN-CT-2000-00037) and the DGICYT, project MAT1999-1063-C04-02.

\section{Notes and references}

1 C. Journet, W. K. Maser, P. Bernier; A. Loiseau, M. Lamy de la Chapelle and S. Lefrant, Nature, 1997, 388, 756.

2 T. Guo, P. Nikolaev, A. Thess, D. T. Colbert and R. E. Smalley, Chem Phys. Lett., 1995, 243, 49.

3 A. Thess, R. Lee, P. Nikolaev, H. Dai, P. Petit, J. Robert, C. Xu, Y. H Lee, S. G. Kim, A. G. Rinzler, D. T. Colbert, G. E. Escuseria, D Tomanek, J. E. Fischer and R. E Smalley, Science, 1996, 273, 483.

4 A. Bachtold, P. Hadley, T. Nakanishi and C. Dekker, Science, 2001, 294, 1317.

5 V. Derycke, R. Martel, J. Appenzeller and Ph. Avouris, Nano Lett. 2001, 1, 453.

6 J. M. Bonard, N. Weiss, H. Kind, T. Stöckli, L. Forro, K. Kern and A. Châtelain, Adv. Mater., 2001, 13, 184.

7 G. S. Duesberg, J. Muster, H. J. Byrne, S. Roth and M. Burghard, Appl. Phys., 1999, 69, 269.

8 M. P. Mingos and D. R. Baghurst, Chem. Soc. Rev., 1991, 20, 1.

9 E. Dujardin, C. Meny, P. Panissod, J. P. Kintzinger, N. Yao and T. W. Ebbesen, Solid State Commun., 2000, 114, 543.

10 Practical Surface Analysis Auger and Photoelectron Spectroscopy, ed. D. Briggs and M. P. Seah, 2nd edn., Chichester, 1990. 